\title{
Film notes
}

\author{
Monty Hempel ${ }^{1}$
}

Published online: 5 May 2015

(C) AESS 2015

Keywords Biodiversity · Conservation biology $\cdot$ Extinction · Passenger pigeon $\cdot$ Eco-film

A century ago, on September 1, 1914, the last surviving passenger pigeon died in the Cincinnati Zoo. The phenomenal collapse of this species and what it says about biodiversity, today, are the subjects of a new film by David Mrazek, a well-respected producer and writer of PBS documentary series, including The Principal Story, a review of the American public school system.

From Billions to None takes off, literally, with the help of CGI 2D animation and quadcopters that provide a bird's-eye view of landscapes in the upper midwest where huge flocks of passenger pigeons (Ectopistes migratorius) regularly darkened the sky for hours, even days, as they flew in search of acorns and other nuts. Probably the most abundant land bird

From Billions to None: The Passenger Pigeon's Flight to Extinction David Mrazek, Producer/Director/Writer

Joel Greenberg, Co-Producer/Co-Writer

Waubansee Productions (2014), runtime $57 \mathrm{~min}$.

Monty Hempel

monty_hempel@redlands.edu

1 University of Redlands, 1200 E. Colton Ave., Redlands, CA 92373, USA in North America and perhaps the world, the passenger pigeon went from superabundance to extinction in only about four decades. The film follows cowriter Joel Greenberg, author of A Feathered River Across the Sky (Bloomsbury USA, 2014), in his quest to help people understand what was lost aesthetically and ecologically with the extinction of the passenger pigeon.

During the course of the film, viewers are treated to insightful interviews with diverse researchers and educators in natural history and conservation biology, including Curt Meine, Barbara Ceiga, Boris Worm, and David Blockstein. Threats to other species-from sharks to Sandhill cranes-are discussed, along with the controversial research project of Ben Novak to bring back the passenger pigeon with the help of biotechnology, part of Stewart Brand's Revive and Restore project.

Classroom teachers will find this film useful for helping students understand the speed with which species extinction can occur, as well as the hidden costs it imposes on both ecosystems and the human psyche. The film is fully accessible by students lacking prior knowledge of conservation biology. Its interdisciplinary treatment of biodiversity makes it particularly useful for introductory-level courses in environmental studies. In addition, the film is remarkably effective at taking what many students might consider a mundane subject - the extinction of a "pigeon" - and developing it into a much larger assessment of biodiversity, in general, and why it truly matters. 